\title{
Microwave-assisted Kabachnik-Fields Reaction in Ionic Liquid
}

\author{
Sang-gi Lee, Jae Kyun Lee, Choong Eui Song, and Dok-Chan Kim ${ }^{*}$ \\ Life Scrences Division. Korea Institute of Science and Technology, P. O. Box 131, Cheongrvang. Seoul 130-650, Korea \\ "Depantment of Chemical Engineering, The University of Seoul, Seoul 130-743, Korea
}

Received March 4. 2002

Keywords : Microwave, Lanthanide triflates, Catalysis, Recycling. Jonic liquid.

In recent years one of the prime concerns of chemists is search for replacements of the conventional organic solvents with environmentally benign ones. In this context, room temperature ionic liquids are increasing interest as reaction media. In particular, utilization of the ionic liquids in matalcatalyzed reactions allowed easy recovery and reuse of the catalysts.' During our on going study on catalyst recycling using ionic liquids, ${ }^{2}$ we interested in the combination of ionic liquids with microwave (MW)-assisted organic reactions. " Ionic liquids consisting entirely of ions could absorb the microwave energy efficiently. Moreover, the risk of an explosion caused by rapid increase of vapor pressure of the solvent can be avoided since ionic liquids have no measurable vapor pressure. In spite of several advantages, only few MW-assisted reactions have been carried out in ionic liquids media and no successful catalyst recycling has been achieved so far: ${ }^{4}$ Here we wish to report our preliminary results on the application of ionic liquids in a MW-assisted reaction.

To demonstrate the utility of ionic liquids for catalyst recycling in $\mathrm{MW}$-assisted metal-catalyzed organic reactions. lanthanide triflates catalyzed Kabachnik-Fields reaction" was chosen as a model reaction. Kabachnik-Fields reaction is one of the effective methods for the synthesis of biologically important $\alpha$-aminophosphonates and has been received a great deal of attention in recent years. "Thus, a solution of benzaldehyde, aniline and diethylphosphite in [bmim] $\left[\mathrm{PF}_{6}\right]$ in the presence of $10 \mathrm{~mol} \%$ of $\mathrm{Yb}(\mathrm{OTf})_{3}$ as a catalyst was irradiated for $20 \mathrm{~s}$ using a domestic MW oven $(2450 \mathrm{MHz}$, $850 \mathrm{~W}$ ), then the reaction mixture was taken out. mixed again for $5 \mathrm{~s}$ and then irradiated again for $20 \mathrm{~s}$. This step was repeated until completion of the reaction ( $c a .2 \mathrm{~min}$ ) to give product in $86 \%$ yield. Surprisingly, when the solvent was changed to $\left[\right.$ bmim] $\left[\mathrm{BF}_{\mathrm{i}}\right]$, the yield was markedly increased, thus, the product was obtained almost quantitatively. However, the yield decreased under thermal condition $\left(120^{\circ} \mathrm{C}, 2\right.$ h. $74 \%)$ or under $\mathrm{MW}$ condition in other ionic liquids $(55 \%$ in $[\mathrm{bmim}][\mathrm{OTt}], 72 \%$ in $\left.[\mathrm{bmim}]\left[\mathrm{SbF}_{6}\right]\right)$ and $\mathrm{DMF}(70 \%)$ (entry 1 in Table 1). The catalytic activities of other catalysts were also examined under MW irradiation (Table I).

As shown in Table 1, all of the catalysts examined exhibited superior catalytic activities in bmim][BF $\left.{ }_{1}\right]$ and [bmim] $\left.\mathrm{PF}_{6}\right]$. For examples. $\mathrm{Yb}(\mathrm{OTf})_{3}$ and Dy $(\mathrm{OTf})_{3}$ showed higher activity in [bıim] $\left[\mathrm{BF}_{4}\right]$ than in other ionic liquids. On the other hand, the catalytic activities of the other catalysts, $\mathrm{Sc}(\mathrm{OTf})_{3,}, \mathrm{Gd}(\mathrm{OTf})_{3}$ and $\operatorname{lnC} 1_{3}$, are superior in [bonim]
Table I. The three component reactions of berraldehyde, aniline adnd diethylphosphite in [bmim][X] or DMI: in the presence of lanthanide triflates and indium trichloride using microwavesect

\begin{tabular}{|c|c|c|c|c|c|c|}
\hline & \multirow{2}{*}{$+\mathrm{Ph}_{-} \mathrm{NH}_{2}$} & \multicolumn{3}{|c|}{$\begin{array}{c}\text { Cat. } \\
(10 \mathrm{~mol} \%)\end{array}$} & \\
\hline & & (1) & [b & $\begin{array}{l}\mathrm{im} \\
(2 \mathrm{~min}\end{array}$ & & it \\
\hline \multirow{2}{*}{ Fintry } & \multirow{2}{*}{ catalyst } & \multicolumn{4}{|c|}{$X$ in $|b m i m||X|$} & \multirow{2}{*}{ IMMt' } \\
\hline & & $\mathrm{PF}_{6}$ & $\mathrm{BF}_{4}$ & OTf & $\mathrm{SbF}_{4}$ & \\
\hline 1 & $\mathrm{Yb}(\mathrm{OTf}) \mathrm{s}$ & 86 & $99(74)^{f t}$ & 55 & 72 & 70 \\
\hline 2 & Sc(OTt); & 88 & 81 & 80 & 63 & 90 \\
\hline 3 & Dyy(OTf): & 87 & 90 & 55 & 80 & 62 \\
\hline 4 & Gd(OTf) & 94 & 62 & 52 & 63 & 65 \\
\hline 5 & {$[\mathrm{nc}]_{\mathrm{i}}$} & 91 & 80 & 70 & 65 & 82 \\
\hline
\end{tabular}

"Aldehyde ( 1 mmol). anilne ( 1.2 mmol $)$, and diethyl phosphite (1.2 mmol) were successively added to a solution of catalyst $(10$ mole \%) in an ionic liguid ( $\mathrm{I} \mathrm{mL}$ ) placed in a flat botom llask, mixed thorouglly on a vortex Mixer (Scientific lnc. Model $(\mathrm{j}-560)$ and the mixture was irradiated intermittently in an unmodified domestic microwave oven. After completion the reaction. the product was isolated by extraction with benzene $(5 \mathrm{~mL} \times 4)$, and purilied by silica columt chromatography. for catalyst recycling. more reactant was added to the ionic liquid containing catalyst "MW irradiated for $2 \min (20 s+20 s+20 s+20 s+$ $20 s+20 \mathrm{~s}$ ). "Isolated yield (average of two runs). "Yield given in parenthesis obtained under thermal condition $\left(120^{\circ} \mathrm{C} .2 \mathrm{~h}\right)$

$\left[\mathrm{PF}_{6}\right]$. Moreover, higher or comparable catalytic activities were observed in ionic liquids compared to the organic solvent, DMF. In the recycling study, the catalyst, $\mathrm{Yb}(\mathrm{OTf})_{\overline{3}}$, immobilized in [bmim] $\left[\mathrm{BF}_{4}\right]$ could be re-used 5 times without any loss of catalytic activity ( $>99 \%$ average yield). This result clearly indicates that both [bmim] $\left[\mathrm{BF}_{4}\right]$ solvent and $\mathrm{Yb}(\mathrm{OTf})_{3}$ catalyst are quite stable upon microwave irradiation. On contrary, the catalytic activity of the same catalyst immobilized in $[\mathrm{bmim}]\left[\mathrm{SbF}_{6}\right]$ was dramatically decreased in the second cycle $(33 \%$ yield). The different catalytic properties of $\mathrm{Yb}(\mathrm{OTf})_{3}$ in $[\mathrm{bmim}]\left[\mathrm{BF}_{1}\right]$ and [bmim] $\left[\mathrm{SbF}_{6}\right]$ may be attributed to the different thermal behavior of the ionic liquids upon MW irradiation. Figure I shows temperatures attained as a function of irradiation time for ionic liquids. [bmim][X], and DMF.

It has been found that the heating rates of the ionic liquids. [bmim][X], are faster than DMF, and largely affected by the counter anion. $X$. The [bmim][OTf] showed the fastest heating rate, thus, the temperature reached $200^{\circ} \mathrm{C}$ after 2 min. It is interesting that the temperature of $[\mathrm{bmim}]\left[\mathrm{PF}_{6}\right]$ and 


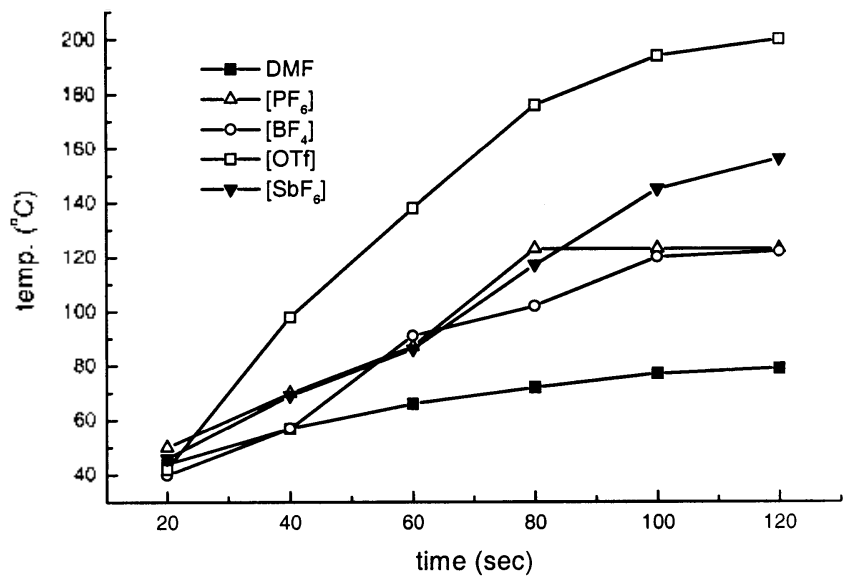

Figure 1. Thermal behaviors of ionie lipuids and D.MF under. MW irradiation. Temperature is the mean average $\left(+5^{\circ} \mathrm{C}\right.$ error range of three measurements.

Table 2. Microwave assisted three component reactions of aldehydes. aniline and dielhy.phosphite in [bomim|lis ${ }_{+}$in the presence of Ybolotis a catalyst

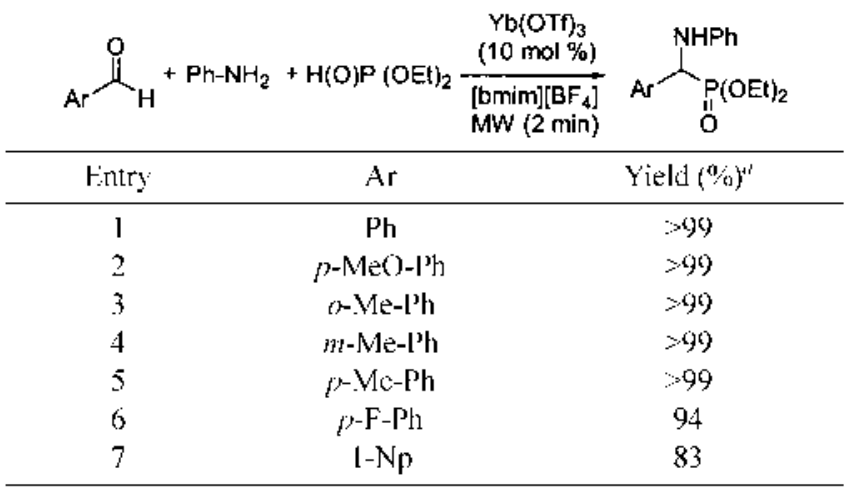

"Isolated yield

[bmim $]\left[\mathrm{BF}_{+}\right]$reached thermal stationary states after $100 \mathrm{sec}$ (ca. $115-120^{\circ} \mathrm{C}$ ). Although it is not clear yet, it may be possible to assume that the high activity and stability of $\mathrm{Yb}\left(\mathrm{O}[\mathrm{f})_{\text {s }}\right.$ in $[\mathrm{bmim}]\left[\mathrm{BH}_{4}\right]$ is largely related with its thermal behavior under $\mathrm{MW}$ irradiation. Finally, numbers of $\alpha$ - aminophosphonates could be rapidly synthesized in excellent yields through MW assisted Kabachnik-Fields reactions and the results are summarized in Table 2 .

In summary, using lanthanide triflates catalyzed KabachnikFields reaction as a model reaction has proved the utility of ionic liquids, [bmim][X], as solvents in MW-assisted metalcatalyzed reactions. Under MW irradiation, the thermal behaviors of ionic liquids and the recyclability of the catalysts were largely affected by the counter anions of [bmim] [X]. A successful recycling of a catalyst. Yb(OTf), immobilized in [bmim] $\left[\mathrm{BF}_{4}\right]$ may open new eco-friendly protocol in MW-assisted metal-catalyzed reactions. Further applications of ionic liquids to other MW-assisted metal-catalyzed reactions are under study,

Acknowledgment. This work was supported from MOST (National Research l.aboratory Program, 2N22890), KIST (2F:17512) and CMDS at KAIST.

\section{References}

1. (a) Welton. T. Chent. Rev 1999. 99. 2071. (b) Wasserscheid. P.: Keim. W. Angew: (hem. ht. Fd. 2000. 39. 3772. (c) Brown. R.

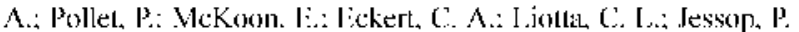
(3. . Am. Chem. Soc. 2001. 123. 1254.

2. (a) Lee. S.-g.: Park. J. H.: Kang. J.: Lee. J. K. Chem. Commun. 2001. 1698, (b) Song. C. E.: Shim. W. H.: Roh. E. J.: Lee. S.-g.: Choi. I. H. Chem. Commun 2001. 1122. (c) Song. C. E.: Oh. C. R.: Roh, F. I.: (hoo. D. J. Chem. Conmm. 2000. 1743.

3. Recent selected reviews for MW-assisted reactions. See (a) Per-

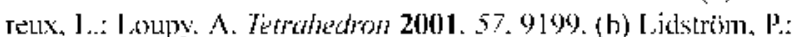
Tiemey. J.: Wathey. B.: Westman. J. Tetrahedron 2001. 57.9225.

4. (a) Dubrcuil. J. F.: Bazurcau. I. P. Tetrohedron Lett. 2000. H/. 7351. (b) Dubreuil. J. F.: Bazurcau. I. P. Tetrohedron Lett. 2001. f2. 6097. (c) Varma. R. S.: Namboodiri. V. V. Pme Appl. Chen. 2001. 73.1309

5. (a) Kabachnik. M. J.: Medved. T. Izv dket. Natzk SSSR 1954. 1126. (b) Firlds. E. K. . A th. Chem. Soc. 1952. 74. 1528.

6. (a) Recent papers for the synthesis of $\alpha$-aminophosphonates. Sec: Qian. C.: Huang. T. J. Oig. Chem. 1998. 63. 4125. (b) Ranu. B. C.: Ilajira A.: Jana U. Org. lett. 1999. I. II4I. (c) Manabe K.: Kobayashi. S. Chem. (ommum. 2000. 669. (d) Kaboudin. B.: Nar.ari. R. Fetrathedron lett. 2001. +2.8211. (e) Chanderasekhalr. S.: l'rakash. S. I. Jagadeshwar. V.: Narsihmulu. C. Tetrothedron Lett. 2001. 4.. 5561 . 